\section{a Cartografia do Cotidiano, Mapas Não Conven- cionals e UM AtLas de NarRativas}

WOOD, Denis. Everything Sings. Maps for a Narrative Atlas. Los Angeles: Siglio, 2010. 110p.

ISBN: 097995642

Jörn Seemann ${ }^{1}$

$M$ pas são construções socioculturais que precisam ser compreendidas a partir dos contextos da sociedade na qual foram produzidas. Como textos culturais, mapas representam objetos de estudo por excelência para que o geógrafo humanista possa levantar questionamentos e responder a perguntas sobre geograficidade e sentido de lugar. Portanto, a ideia exclusiva da cartografia como ciência objetiva e exata e a concepção do mapa como espelho da realidade ainda dominam o pensamento de muitos geógrafos. Essa visão da cartografia impede um entrosamento maior com essas

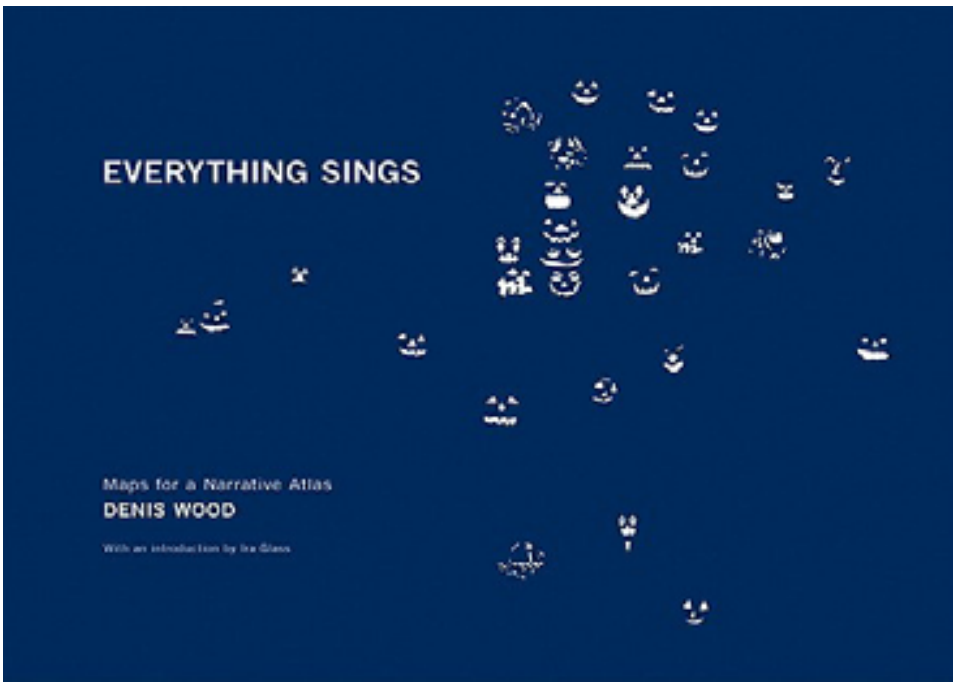
representações cartográficas nas pesquisas.

Há mais de quatro décadas, o geógrafo americano Denis Wood está produzindo artigos, livros, poemas e performances que estimulam e provocam uma reflexão mais aprofundada sobre a dimensão humanista na cartografia. Wood ganhou uma certa notoriedade

1 Doutor em Geografia. Professor Adjunto da Universidade Regional do Cariri (URCA). jornseemann@gmail.com

$\triangle 1$ Universidade Regional do Cariri, Centro de Humanidades, Departamento de Geociências. Rua Coronel Antônio Luiz, 1161, Pimenta. 63105-000. Crato, CE.

Geograficidade v.01, n.01, Inverno 2011

ISSN: 2238-0205 com o seu estilo irreverente de escrever e a sua maneira criativa de expressar seus pontos de vista, principalmente no seu livro The Power of Maps ("O poder dos mapas", WOOD, 1992), que 19 anos depois do seu lançamento ainda está aguardando uma tradução para o português. Na sua vasta produção acadêmica e artística, Wood criticamente desconstrói os mapas, revelando-os como discursos, máscaras do poder ou proposições intencionais. Nos seus projetos, ele não despreza cartografias do dia a dia feitas por pessoas comuns e não por profissionais (por exemplo, mapeamentos comunitários). A análise de elementos cartográficos na literatura infantil, na arte e nas contraculturas faz parte do seu repertório (veja o site pessoal de Wood na internet: http:// deniswood.net).

O mais recente livro de Wood é Everything Sings. Maps for a Narrative Atlas. O volume fino de 110 páginas é dividido em duas partes. A introdução do livro visa a apresentar a filosofia cartográfica que norteia o atlas e o objeto do estudo, o bairro de Boylan Heights na cidade de Raleigh, na Carolina do Norte. A segunda parte consiste no conjunto de mapas do bairro sobre os quais Wood fornece informações e detalhes complementares.

Na verdade, não se trata de um trabalho recente, mas é fruto de um projeto antigo que Wood realizou com os seus estudantes de desenho gráfico da North Carolina State University, desde meados dos anos 70 até 1982. A partir das suas observações sobre esses exercícios, Wood chegou à conclusão de que o arruamento do bairro servia como um "esqueleto" pre-definido para os alunos que limitava a visão do mapeador. Desafiando as regras da cartografia convencional, Wood 
A Cartografia do Cotidiano, Mapas Não Convencionais e um Atlas de Narrativas

foi à procura de representações diferentes que tratavam de valores humanos e mexiam com as nossas emoções.

$\mathrm{Na}$ introdução do livro, ele explica que os mapas do atlas não se baseiam, necessariamente, nas convenções cartográficas, mas procuram contar histórias ou, nas palavras do autor, narrativas, de modo que o conjunto desses mapas torna-se "um atlas de uma vizinhança que você pode ler como se fosse um romance" (p.g). Para Wood, esse atlas "está arraigado em um sentido profundo de lugar... repleto de ricos caracteres humanos, abundante de eventos" (p.g). Aludindo ao título do livro, tudo no atlas "está cantando", enquanto os mapas de Wood tornam-se verdadeiros poemas e formas criativas de arte, que buscam celebrar as coisas do cotidiano e procuram representar o que fica invisível ou o que é normalmente deixado de fora do mapa.

Qual e a aparência desses quase quarenta mapas poéticos que Wood incluiu em seu atlas narrativo? Alguns dos mapas são representações bastante convencionais, como um simples mapa de localização, uma foto aérea, um mapa do relevo ou a rota do carteiro pelo bairro, enquanto outros são muito mais abstrusos ou até intrigantes. Wood omite os traçados das ruas na maioria dos seus mapas. Ele representa a posição de cada árvore no bairro, o seu estado de preservação (intato, cortado, podado, mutilado), sua idade, seu tamanho e sua situação legal (pública, privada). Outros mapas mostram os diferentes tipos de cercas no bairro ( 16 classes no total), os textos dos grafiti nos muros das casas, as placas de trânsito e as "rodovias arbóreas" usadas pelos esquilos. Alguns desenhos são extremamente abstratos e não revelam suas qualidades espaciais à primeira vista. É preciso olhar com atenção. Por exemplo, o mapa com o título "Chamadas para a polícia" apenas contém uma "salada de números" de 1 a 38 que reconstrói o traçado das ruas, sendo que cada número corresponde a um tipo de queixa diferente (mordida de cachorro, assalto, briga, incêndio etc.). 0 tamanho de cada item é proporcional ao número de ocorrências. Dessa maneira, o leitor do mapa não apenas chega a saber que o número 17 (acidente de carro) é mais frequente, mas também consegue localizar todos os cruzamentos maiores do bairro nos quais o 17 aparece sem falta.

No tópico "folhas do outuno", por sua vez, Wood originalmente usava lápis de cor para indicar a cor dominante da folhagem das árvores do bairro. Para o atlas que não contém ilustrações coloridas, ele teve que substituir as cores por palavras como verde, amarelo, vermelho ou dourado. O resultado é o contorno do bairro preenchido com mais do que duzentas palavras em fontes e estilos diferentes.

O mapa mais curioso do atlas distingue-se dos outros. Sob um fundo preto aparecem caretas que simbolizam o acabamento particular de cada abóbora de Halloween que os moradores do bairro deixaram à exposição nas suas varandas. Wood nos conta que, em 1982, ele andava de bicicleta pela vizinhança e tirava fotos de todas as abóboras que encontrava nas frentes das casas.

Cismando sobre esses mapas - e não mencionei todos que fazem parte do atlas -, podemos nos perguntar qual é o sentido desses desenhos. O profissional de cartografia bem pode reclamar de uma "quebra de decoro cartográfico", já que Wood dispensa alguns elementos obrigatórios de um mapa, como escala ou a indicação do norte. No entanto, com os seus mapas, Wood não objetiva representar a fria geometria do espaço geográfico com todas as suas medidas e configurações, mas propõe uma "cartografia da realidade". Essa cartografia "não se baseia em abstrações insuspeitas e não suportadas do enésimo grau, mas precisa ser enraizada na experiência cotidiana" (WOOD, 1978, p. 207).

Everything Sings é um festival de ideias e inspirações para o uso criativo de mapas nas pesquisas e no dia a dia. É um convite não 
apenas para ler essas cartografias alternativas, mas também para ativamente produzir os nossos próprios mapas e as nossas narrativas, seja em forma de um atlas municipal que dá mais vez e voz aos atores sociais, um mapa do olfato, produzido durante um jogo de futebol no Maracanã, ou um mapeamento temático dos problemas de uma favela. À medida que a geograficidade tornou-se um conceito muito importante para a geografia humanística, a "cartograficidade" que Wood apresenta nesse volume poderia abrir novos caminhos para repensar os mapas, criar novas maneiras de representar paisagens e captar a dimensão humana do lugar.

\section{Referências}

WOOD, Denis. Introducing the Cartography of Reality. In: LEY, David; SAMUELS, Marwyn. (Orgs.) Humanistic Geography: Prospects and Problems. Chicago: Maaroufa Press, 1978. p.207-219.

. The Power of Maps. New York: Guilford Press, 1992. 